\title{
Influence of Energy Parameters on Plasma Radius, Energy Fraction and Plasma Flushing Efficiency for a Single Discharge in EDM
}

Bibeka Nanda Padhi

Indian Institute of Technology Kanpur

Sounak Kumar Choudhury

Indian Institute of Technology Kanpur

Ramkumar Janakarajan ( $\sim$ jrkumar@iitk.ac.in )

Indian Institute of Technology Kanpur

\section{Research Article}

Keywords: Fraction of energy, plasma flushing efficiency, plasma radius, crater depth, crater radius and recast layer thickness.

Posted Date: April 30th, 2021

DOl: https://doi.org/10.21203/rs.3.rs-362696/v1

License: (c) (i) This work is licensed under a Creative Commons Attribution 4.0 International License. Read Full License 
Influence of energy parameters on plasma radius, energy fraction and plasma flushing efficiency for a single discharge in EDM

Bibeka Nanda Padhi ${ }^{1}$, Sounak Kumar Choudhury ${ }^{1}$ and Ramkumar Janakarajan ${ }^{1 \text {, * }}$

${ }^{1}$ Mechanical Engineering Department, Indian Institute of Technology Kanpur, Kanpur - 208016, INDIA Corresponding author: Ramkumar Janakarajan*

Email: jrkumar@iitk.ac.in* 


\begin{abstract}
An electrical discharge forms a crater on the workpiece surface. The crater morphology estimates the performance parameters of the electrical discharge machining process. The energy parameters (gap voltage, discharge current and the pulse on time), the plasma channel radius and the energy fraction coming to the workpiece determine the molten cavity radius and depth. The plasma flushes away a portion of material from the molten cavity forming a crater and resolidification of the remaining molten material forms a recast layer. The plasma flushing efficiency determines the crater's radius and depth. Few researchers have successfully expressed the plasma radius, energy fraction and plasma flushing efficiency in relation to two of the energy parameters, namely, discharge current and pulse on time but not as a gap voltage function. This work attempted to develop a thermo-physical model to express plasma radius, energy fraction and plasma flushing efficiency as a function of all three energy parameters, such as gap voltage, discharge current and pulse on time. Plasma flushing efficiency was calculated and plasma radius and energy fraction were estimated by inverse finite element method from the measured values of crater radius, crater depth and recast layer thickness. The expressions for plasma radius, energy fraction and plasma flushing efficiency were found out from the regression equations obtained from the designed data set using the Taguchi method. Validation shows that the modeled and experimental values of crater radius, crater depth, and recast layer thickness agree well.
\end{abstract}

Keywords: Fraction of energy, plasma flushing efficiency, plasma radius, crater depth, crater radius and recast layer thickness. 


\section{Introduction}

Electro discharge machining (EDM) is a non-traditional machining process that uses a thermoelectric energy source for material removal from conductive materials by melting and vaporization. This process is used to machine hard materials as the material removal mechanism is not affected by hardness. This process is also used to fabricate complex features in the various conductive materials as accuracy and precision are characteristic features of this process [1]. Gap voltage $\left(\mathrm{V}_{\mathrm{g}}\right)$ discharge current $\left(\mathrm{I}_{\mathrm{d}}\right)$ and pulse on time $\left(\mathrm{T}_{\mathrm{on}}\right)$ are the important energy parameters of the process [2].

In the EDM process, both the workpiece and the tool used are conductive. They are connected to the terminals of the power supply being submerged in a dielectric fluid, maintaining a tiny gap in the order of 20-50 $\mu \mathrm{m}$. When power is supplied in this condition, a series of electrical discharges occur. During a discharge, electrons emitted by the cathode move towards the anode. They ionize the dielectric molecules to form ions as they move [3]. Electrons are bombarded on the anode surface and conversion of their kinetic energy to heat energy occurs. Part of that heat energy melts and vaporizes the anode material and the dielectric fluid absorbs the remaining heat energy. Similarly, ions are bombarded on the cathode surface and conversion of their kinetic energy to heat energy occurs. Part of that heat energy melts and vaporizes material from the cathode and the dielectric fluid absorbs the remaining heat energy. The ions and electrons in the plasma state move at very high speed in discharge location. The plasma is a very high-pressure channel. When no supply of power at the start of the pulse off time, the plasma collapses, resulting in a mechanical blast that removes molten material from both the cathode and the anode. The remaining molten material resolidifies to form a recast layer[4].

Fig.1 
In the melt pool, the temperature is maximum at the point where the axis of plasma meets the surface and the temperature decreases as we move away towards the melt pool boundary. The temperature at the melt pool boundary is the melting point temperature[5]. The molten material near the melt pool boundary is at a lower temperature and has a higher viscosity than the molten metal at the center of the melt pool. Hence the force exerted due to plasma collapse used to remove material from the melt pool is insufficient to remove the highly viscous molten metal present near the melt pool boundary but sufficient to displace it upward before resolidification [6]. Due to the displacement of the molten metal, part of it comes above the workpiece surface, forming a bulged region. The bulged portion helps determine the resolidified molten cavity diameter [7]. Also, the superheated metal is removed to the inter-electrode gap in the form of bubbles and the molten metal is released to the inter-electrode gap and gets resolidified to form debris. Bubbles are also formed by superheating of tool material and dielectric fluid [8]. Based on the above studies, a schematic diagram is made to show the affected region of an electrode surface due to electrical discharge before and after plasma collapse or plasma flushing, as shown in Fig. 1(a) and Fig. 1(b), respectively.

Due to melting and vaporization, a very small amount of material is removed during an electrical discharge, leaving a crater on both the work material and tool surfaces. The workpiece's crater geometry can be used to estimate performance parameters such as material removal rate $(M R R)$ and surface roughness $(S R)$. The crater geometry of the tool surface is helpful to predict tool wear rate $(T W R)$. The operating parameters $V_{g}, I_{d}$ and $T_{o n}$ have a significant influence on these performance parameters [9]. Along with the operating parameters, pulse energy fractions going to the cathode $\left(F_{c}\right)$ and anode $\left(F_{a}\right)$ along with plasma channel radius $\left(R_{p}\right)$ are also input to the thermo-physical model used to predict melt geometry. After estimating melt geometry from the model, plasma flushing efficiency $(P F E)$ is required to estimate the final crater geometry for a single discharge [10]. 
Few notable initial models have been discussed here. In the electro-thermal model developed by Snoeys and Van Dijck [11] for an electrical discharge, a disc source of heat was considered on a semi-infinite cylinder. Complete conversion of electrical energy into thermal energy and equal distribution between anode and cathode was assumed. The work was extended by Van Dijck and Dutre [12] by developing a two-dimensional thermal model considering both finite and infinite depth in the Z-direction. Beck [13] used another approach by considering a disc heat source on a semi-infinite cylinder, where the region beyond the disc heat source was considered insulated. Constant values of heat flux radius and material properties have been used for the analysis. The $F_{c}$ of value 0.5 has been used in the aforementioned models and the predicted value of $M R R$ was found very high compared to the measured value of $M R R$ in each of the cases. In the model of Jilani and Pandey [14], also disc heat source with a constant radius was taken, but it was assumed that $90 \%$ of the discharge energy is equally distributed between anode and cathode. Also, the disc heat source radius remained constant for any discharge conditions. Here a better prediction of $M R R$ was obtained than the previous models. Dibitonto et al. [15] have used the value of $F_{c} 0.18$ in a point heat source model for the analysis, where the prediction of MRR was obtained even better than Jilani and Pandey model. Yeo et al. [16] reviewed all the aforementioned work critically and concluded that the work of Dibitonto et al. the prediction of $M R R$ was nearest to the measured value, whereas the shape of the cavity for a single discharge was predicted hemispherical. Though the other models did not predict well the $M R R$, they have the potential to predict better both the shape of the cavity and $M R R$ by proper approximation of heat flux radius and the fraction of energy.

Ben Salah et al. [17] numerically modeled temperature distribution for a single discharge to predict $M R R$ and $S R$ in an EDM process. In their study, the fraction of generated energy going to the workpiece was considered 0.08 and a Gaussian heat source was used. Temperaturedependent thermal conductivity was also used, which showed a better correlation between 
numerical and experimental results. Joshi and Pandey [18] developed a nonlinear transient thermo-physical model for a die-sinking variant of the EDM process. Gaussian heat source with discharge current and discharge duration-dependent heat flux radius was used considering latent heat of melting. The values of $F_{c}$ used for the analysis were $0.183,0.2,0.25$ and 0.3 . Out of those values, 0.183 was recommended for low energy pulses and 0.2 for medium energy pulses. In the work of Singh [19], $F_{c}$ was estimated in relation to discharge current and discharge duration indirectly by temperature measurement by different locations. Ming et al. [20] have also used the expression of $F_{c}$ in relation to $V_{g}$ and $I_{d}$. The temperature was measured at different locations in tool, workpiece and dielectric to measure stored energy and $F_{c}$ using heat transfer equations. Shabgard et al. [10] did a detailed investigation using Gaussian heat source and plasma radius dependent on discharge duration and discharge current and demonstrated that fractions of energy going to both tool and workpiece were dependent on pulse current and pulse duration. Crater dimensions and recast layer thickness were measured to determine melt geometry and from melt geometry and crater geometry, PFE was calculated. PFE was found to be a pulse on time and discharge current dependent. Jitin et al. [21] modeled textured surface and $S R$ of an EDMed surface. The values of $F_{c}$ taken for low $(<50 \mathrm{mj})$, medium (50-100 mj) and high (> $100 \mathrm{mj}$ ) pulse energy zones were $0.109,0.187$ and 0.256 , respectively. The regression equations obtained by Shabgard et al. [10] were used for the calculation of PFE. $V_{g}$ is a significant parameter in the EDM process. As the gap voltage contributes to the pulse energy, it affects performance parameters of EDM like $M R R, S R$, overcut, recast layer thickness, etc. To study the influence of $V_{g}$ on crater geometry, the $R_{p}$ must be expressed as a function of $V_{g}$ also, along with $I_{d}$ and $T_{o n}$. In the present work, efforts have been made to define $R_{p}$ as a function of $V_{g}, I_{d}$ and $T_{o n}$. Also, the effect of $V_{g}, I_{d}$ and $T_{o n}$ on $F_{c}$ and $P F E$ has been studied. 


\section{Thermophysical model of EDM}

COMSOL Multiphysics 5.2 software has been employed to numerically simulate the thermophysical model using the finite element method for a single discharge. A 2D axisymmetric physical domain and heat transfer in a solid interface has been used for the simulation. Discretization of the geometry was done with 3-node triangular elements and linear shape functions. An extremely fine setting of the triangular elements has been selected for meshing. The assumptions made for this model are as follows:

1. The material of the workpiece is homogeneous and isotropic in nature.

2. The properties of the material are temperature-independent.

3. During a discharge, heat flows to the workpiece from the plasma by conduction only.

4. Model is developed for an individual electrical discharge and distribution of heat flux is uniform in every discharge.

5. An electrical discharge removes a very small amount of material compared to the volume of electrodes. Hence electrodes are assumed to be semi-infinite bodies.

6. Thermal effects of previous discharge are not considered.

7. The surface topology effect was neglected by assuming electrode surfaces to be flat and parallel to each other.

8. The inter-electrode gap does not affect the characteristics of an electrical discharge.

9. The shape of each crater formed is assumed to be a circular paraboloid.

10. For each discharge, the recast layer formed is uniform.

Fig.2

\subsection{Governing equation and boundary conditions}


The differential equation of heat conduction without internal heat generation is used as the governing equation to describe the state of heat distribution on the workpiece for every discharge [10][22].

$\frac{1}{r} \frac{\partial}{\partial r}\left(K r \frac{\partial T}{\partial r}\right)+\frac{\partial}{\partial z}\left(K \frac{\partial T}{\partial z}\right)=\rho C_{1} \frac{\partial T}{\partial t}$

Where coordinates of a cylindrical domain are $\mathrm{r}$ and $\mathrm{z}$, as depicted in Fig. 2(a), $\mathrm{K}$ is thermal conductivity, $\mathrm{T}$ is temperature, $\rho$ is density, $\mathrm{C}_{1}$ is the effective specific heat with consideration of the latent heat of the workpiece and $\mathrm{t}$ is the time. For the analysis, the temperature of the domain is taken the atmospheric temperature $\mathrm{T}_{0}$ initially. Boundary 1 is the top surface in contact with the dielectric medium on which heat flux is applied [18]. The boundary condition for this surface is expressed below.

$$
\begin{gathered}
K \frac{\partial T}{\partial z}=\left\{\begin{array}{c}
q(r)\left(r<R_{p}\right) \\
0\left(r>R_{p}\right) \\
0 \text { for off time }
\end{array}\right. \\
\text { and } \frac{\partial T}{\partial n}=0 \text { on } B_{2}, B_{3} \text { and } B_{4}
\end{gathered}
$$

As per the assumptions, heat transfer from plasma to the workpiece happens by conduction which melts and vaporizes material from the workpiece on discharge location. A single discharge is analyzed and considering all discharges are identical. The analysis is further extended to find the result of multiple discharges. A small volume of cylindrical shape around the plasma is chosen for analysis of the two-dimensional axisymmetric process continuum.

\subsection{Heat input}

The parameters of heat input are pulse energy, distribution of energy and $F_{c}$. For a discharge, the pulse energy is the product of $V_{g}, I_{d}$ and $T_{o n}$. In the present work, the Gaussian distribution of heat flux input is used to approximate the heat conducted from plasma to workpiece as it 
predicts crater shape better than uniform heat distribution [12]. The heat conducted from plasma to workpiece can be expressed as

$$
q(r)=q_{0} \exp \left\{-4.5\left(\frac{r}{R_{p}}\right)^{2}\right\}
$$

Calculation of the maximum heat flux $q_{0}$ can be done by using the formula under

$q_{0}=\frac{4.57 F_{c} V_{g} I_{d}}{\pi R_{p}^{2}}$

Where, the fraction of energy of plasma entering to the cathode is $F_{c}$, gap voltage is $V_{g}$, the discharge current is $I_{d}$ and the plasma radius on the cathode surface is $R_{p}$.

$R_{p}$ is more often used as a function of $I_{d}$ and $T_{o n}[23]$ expressed below.

$R_{p}=2.04 I_{d}^{0.43} T_{o n}^{0.44}$

This expression cannot take care of the variation of plasma radius with $V_{g}$. In this work, by inverse FEM attempt has been made to express it as

$$
R_{p}=R_{p}\left(V_{g}, I_{d}, T_{o n}\right)
$$

\subsection{Morphology of the molten cavity and crater}

The molten cavity dimensions and the crater dimensions are schematically represented in Fig. 2(b). At the melting temperature of the cathode material, the isothermal contour obtained by the numerical simulation of the thermo-physical modeled molten cavity. The modeled molten cavity, as well as the actual crater formed due to electrical discharge, are parabolic [23]. The molten cavity volume can be calculated by using the molten cavity dimensions [18].

$V_{M T}=\frac{1}{2} \pi D_{M T} R_{M T}^{2}$ 
where, $V_{M T}$ is the theoretical volume of the molten cavity obtained from dimensions of isothermal contour at melting temperature. $R_{M T}$ and $D_{M T}$ are the radius and the depth of the molten cavity obtained from the numerical simulation of the thermo-physical model, respectively.

After plasma flushing of the molten material, the volume of the crater formed can be calculated using the crater dimensions.

$$
V_{C T}=\frac{1}{2} \pi D_{C T} R_{C T}^{2}
$$

where $V_{C T}$ is the theoretical volume of the crater obtained from dimensions of the crater. $R_{C T}$ and $D_{C T}$ are the theoretical radius and the depth of the crater, respectively.

From the volume of the molten cavity and volume of the crater, the plasma flushing efficiency is calculated.

$$
P F E=\frac{V_{C T}}{V_{M T}}
$$

where PFE is the plasma flushing efficiency.

For the identical shape of the molten cavity and the crater, the plasma flushing efficiency relates the dimensions of the molten cavity and the crater as expressed below [21].

$$
P F E=\left(\frac{R_{C T}}{R_{C T}}\right)^{\frac{1}{3}}=\left(\frac{D_{C T}}{D_{C T}}\right)^{\frac{1}{3}}
$$

The theoretical recast layer thickness can also be calculated by using the expression below [11].

$$
R L T_{T}=D_{M T}-D_{C T}
$$

Where, $R L T_{T}$ is the theoretical recast layer thickness.

\section{Experimental procedure}


On a "Elektra R-50-ZNC" die-sinking electrical discharge machine, the experiments are conducted. The Z-axis of the is servo-controlled. A copper foil with a one-dimensional array of micropillars has been used as the tool for generating the single discharges on a polished surface of D2 steel. The tool was made anode and the workpiece was made cathode by connecting to the positive and negative terminal of the power supply, respectively. The chemical composition and the material properties used in the thermophysical model of D2 steel are listed in Table 1 and Table 2, respectively.

Fig.3

An electrical discharge forms a crater on the workpiece surface and removes a small amount of material from a micropillar of the tool with a very small cross-sectional area $(80 \mu \mathrm{m} \times 80$ $\mu \mathrm{m})$. The removal of material from both the workpiece and tool at the discharge location made the Inter-electrode gap (IEG) high enough for another discharge not to happen at that location. The images of the tool with the micropillars and the craters formed due to single discharges on the workpiece taken using Dino-Lite digital microscope are depicted in Fig. 3(a) and Fig. 3(b), respectively.

\section{Table 1}

Table 2

\section{Fig.4}

Contour-GT-K optical 3D profilometer from Bruker has been used to measure the diameter and the depth of a crater. The 3D profile, 2D top-view and ZX profile of a crater formed at 40 V, $32 \mathrm{~A}$ and $150 \mu \mathrm{s}$ are shown in Fig. 4(a), Fig. 4(b) and Fig. 4(c), respectively. The measurement of the crater diameter and the molten cavity diameter are shown in Fig. 4(b). Due 
to single electrical discharges, the molten cavities and the craters formed were not axisymmetric. So, the mean of the diameters measured in both the $\mathrm{X}$ and $\mathrm{Y}$ directions were used for the analysis of both the crater and the molten cavity. The measurement of the crater depth from its ZX profile is shown in Fig. 4(c). Nikon-Eclipse-LV-100 optical microscope has been used to measure recast layer thickness. During measurement of the recast layer thickness, the section of an ED-machined surface was created, then polished and etched. The recast layer formed at $40 \mathrm{~V}, 32 \mathrm{~A}$ and $150 \mu$ s is shown in Fig 4.d. The mean value of the $R L T$ measured at ten places for a section was used for the analysis.

The methodology adopted to evaluate the $R_{p}, F_{c}$ and $P F E$ is explained here with an example of discharge that occurred at the gap voltage of $80 \mathrm{~V}$, discharge current of $16 \mathrm{~A}$ and pulse on time of $150 \mu$ s. The diameter of the molten cavity measured in both the $\mathrm{X}$ and $\mathrm{Y}$ directions were $\emptyset_{M X}$ and $\emptyset_{M X}$, respectively, as shown in Fig. 4(b). Then the experimental molten cavity radius $\left(R_{M E}\right)$ was calculated using the expression below.

$R_{M E}=\frac{1}{4}\left(\emptyset_{M X}+\emptyset_{M Y}\right)$

Putting the values $\emptyset_{M X}=248.5 \mu \mathrm{m}$ and $\emptyset_{M Y}=255.4 \mu \mathrm{m}$ in the above expression, the $R_{M E}$ was calculated to be $126.45 \mu \mathrm{m}$.

The diameter of the crater measured in both the $\mathrm{X}$ and $\mathrm{Y}$ directions were $\emptyset_{C X}$ and $\emptyset_{C Y}$, respectively, as shown in Fig. 4(b). Then to calculate the experimental crater radius $\left(R_{C E}\right)$, the following expression was used.

$R_{C E}=\frac{1}{4}\left(\emptyset_{C X}+\emptyset_{C Y}\right)$

Putting the values $\emptyset_{C X}=179.6 \mu \mathrm{m}$ and $\emptyset_{C Y}=183.7 \mu \mathrm{m}$ in the above expression, the $R_{C E}$ was calculated to be $90.83 \mu \mathrm{m}$. 
The depth of the crater $\left(D_{C E}\right)$ measurement is shown in Fig. 4(c) and the recast layer thickness $\left(R L T_{E}\right)$ is shown in Fig. 4(d). The average of the recast layer thickness measured at ten locations was considered for analysis. Then the radius of the molten cavity was calculated using the expression below.

$D_{M E}=D_{C E}+R L T_{E}$

Putting the values $D_{C E}=39.7 \mu \mathrm{m}$ and $R L T_{E}=13.44 \mu \mathrm{m}$ in the above expression, the $D_{M E}$ was calculated to be $53.14 \mu \mathrm{m}$.

Then the experimental crater volume $\left(V_{C E}\right)$ was calculated using the following expression

$V_{C E}=\frac{1}{2} \pi D_{C E} R_{C E}^{2}$

and the experimental molten cavity volume $\left(\mathrm{V}_{\mathrm{ME}}\right)$ was calculated using the following expression.

$V_{M E}=\frac{1}{2} \pi D_{M E} R_{M E}^{2}$

After that, $P F E$ was calculated using the expression below.

$P F E=\frac{V_{C E}}{V_{M E}}=\frac{D_{C E} R_{C E}^{2}}{D_{M E} R_{M E}^{2}}$

Putting the values of $D_{C E}=39.7 \mu \mathrm{m}, D_{M E}=53.14 \mu \mathrm{m}, R_{C E}=90.83 \mu \mathrm{m}$ and $R_{M E}=126.45 \mu \mathrm{m}$ in the above expression, the PFE was calculated to be $38.55 \%$.

Then the process parameters at which the experiment was performed were used in the numerical simulation of the thermo-physical model and the values of $R_{p}$ and $F_{c}$ were so adjusted in the Eqs. (4) and (5) that $R_{M T}$ equaled to $R_{M E}$ and $D_{M T}$ equaled to $D_{M E}$. The adjusted value of the $R_{p}$ and $F_{c}$ at which experimentally found molten cavity fitted the isothermal contour at the melting point were $22.1 \%$ and $146.7 \mu \mathrm{m}$, respectively. 


\section{Fig.5}

The Isothermal contour simulated by COMSOL 5.2 software at the melting point is shown in Fig. 5(a). The 3D view of the temperature distribution is shown in Fig. 5(b).

Three craters for a set of parameters have been considered and the mean values of $R_{M E}, R_{C E}$ and $D_{C E}$ were calculated. Also, the mean of the $\operatorname{RLT}_{\mathrm{E}}$ measured at three sections for a set of parameters was calculated. The average standard deviation is $8.2 \%$ for $R_{M E}, 9.3 \%$ for $R_{C E}$, $11.7 \%$ for $D_{C E}$ and $7.8 \%$ for $R L T_{E}$.

For the design of experiments, the Taguchi method has been employed. Input parameters selected as factors were $V_{g}, I_{d}$ and $T_{o n}$. The output parameters selected as responses were $R_{p}$, $F_{C}$ and $P F E$. The $\mathrm{L}_{16}$ orthogonal array has been chosen to accommodate three factors and four levels of the process parameters. This method reduced the numbers of experiments to 16 from $4^{3}=64$ (used for full factorial) using 4 levels for each of the three input parameters. The input parameters and their levels are listed in Table 3. The responses at the sets of parameters obtained in the DOE are listed in Table 4. The trend lines of the Taguchi method and the percentage of contribution of different process parameters derived from the ANOVA table are used to study the influence of input factors on response parameters.

\section{Table 3}

\section{Results and Discussion}

\subsection{Regression analysis}

Regression analysis was done to the experimental data obtained from Taguchi method runs listed in Table 4. On the analysis, models with significant input factor effects were obtained for $R_{p}, F_{c}$ and $P F E$.

\section{Table 4}




\subsubsection{Influence of input factors on $R_{p}$}

The regression model developed through obtained $R_{p}$ has a higher $F$ (Fisher) value of 51.97, as compared to the standard value from the $F$ distribution table. This means the model is significant for the selected confidence interval (95\%) and can be used for predicting $R_{p}$. The p-value for the model is 0.0001 , which implies there is a chance of only $0.01 \%$ that such a higher $F$-value of the model could happen due to noise. The obtained $R^{2}$ adjusted value for the model is $89.3 \%$, which implies a very good correlation between the process parameter $V_{g}, I_{d}$ and $T_{o n}$ with the considered response $R_{p}$. It has been found that the $R_{p}$ increases with an increase in all the three-process parameters $V_{g}, I_{d}$ and $T_{o n}$, the same can be depicted from Fig. 6. The ANOVA table for the obtained $R_{p}$ data is shown in Table 5. From the ANOVA table it can be seen that the $p$-value for all the parameters is less than 0.05 , which shows the significant influence of all the parameters on the response $R_{p}$. The regression equation of $R_{p}$ in relation to $V_{g}, I_{d}$ and $T_{o n}$ is stated in Eq. (19).

$R_{p}=-9.88+0.775 V_{g}+1.765 I_{d}+0.3264 T_{\text {on }}$

\section{Table 5}

\section{Fig.6}

The increase in $R_{p}$ due to the increase in $V_{g}, I_{d}$ and $T_{o n}$ found in this work is in line with the reported work reported by Kojima et al. [24]. Ikai et al. has formulated $R_{p}$ in relation to $I_{d}$ and $T_{o n}$. In this work, $R_{p}$ is formulated in relation to $V_{g}$ also along with $I_{d}$ and $T_{o n}$.

\subsubsection{Influence of input factors on $F_{c}$}

The regression model developed through obtained $F_{c}$ has a higher $F$-value of 19.64 , as compared to the standard value from the $F$ distribution table. This means the model is significant for the selected confidence interval (95\%) and can be used for predicting $F_{c}$. The $p$ - 
value for the model is 0.0001 , which implies there is a chance of only $0.01 \%$ that such a higher $F$-value of the model could happen due to noise. The obtained $R^{2}$ adjusted value for the model is $86.7 \%$, which implies a very good correlation between the process parameter $V_{g}, I_{d}$ and $T_{o n}$ with the considered response $F_{c}$. It has been found that the $F_{c}$ decreases with an increase in $V_{g}$ and $I_{d}$ and decreases with an increase in $T_{o n}$; the same can be depicted from Fig. 7. The ANOVA table for the obtained $F_{c}$ data is shown in Table 6. From the ANOVA table, it can be understood that the $p$-value for all the parameters is less than 0.05 , which shows the significant influence of all the parameters on the response $F_{c}$. The regression equation of $F_{c}$ in relation to $V_{g}, I_{d}$ and $T_{o n}$ is stated in Eq. (20).

$$
F_{c}=27.49-0.1114 V_{g}-0.2523 I_{d}+0.04428 T_{\text {on }}
$$

\section{Table 6}

The decrease in $F_{c}$ with the increase in $I_{d}$ and increase in $F_{c}$ with an increase in $T_{o n}$ has already been observed by Kliuev at al. [25] and Shabgard et al. [10]. It is also observed in this work that the $F_{c}$ decreases with an increase in $V_{g}$.

\section{Fig.7}

\subsubsection{Influence of input factors on PFE}

The regression model developed through obtained PFE has a higher $F$-value of 28.77 , as compared to the standard value from the $F$ distribution table. This means the model is significant for the selected confidence interval $(95 \%)$ and can be used for predicting PFE. The $p$-value for the model is 0.0001 , which implies there is a chance of only $0.01 \%$ that such a higher $F$-value of the model could happen due to noise. The obtained $R^{2}$ adjusted value for the model is $89.3 \%$, which implies a very good correlation between the process parameter $V_{g}, I_{d}$ and $T_{o n}$ with the considered response $P F E$. It has been found that the PFE increases with an increase in $V_{g}$ and $I_{d}$ and decreases with a decrease in $T_{o n}$; the same can be depicted from Fig. 
8. The ANOVA table for the obtained PFE data is shown in Table 7. From the ANOVA table, it can be observed that the p-value for all the parameters is less than 0.05 , which shows the significant influence of all the parameters on the response PFE. The regression equation of $P F E$ in relation to $V_{g}, I_{d}$ and $T_{o n}$ is stated in Eq. (21).

$$
P F E=23.78+0.1560 V_{g}+0.7438 I_{d}-0.0372 T_{\text {on }}
$$

\section{Table 7}

Fig.8

The increase in $P F E$ with the increase in $I_{d}$ and decrease in $P F E$ with the increase in $T_{o n}$ is in line with the work reported by Shabgard et al. [10]. It is also observed in this work that the $P F E$ increases with an increase in $V_{g}$.

The obtained values of $R_{p}, F_{c}$ and $P F E$ from Eqs. (19-21) for a set of process parameters that can be used will be helpful in predicting crater geometry and recast layer thickness.

\subsection{Model validation}

To validate the developed thermo-physical model in the present work, at the identical combination of the process parameters, the experimentally measured $R L T_{E}, D_{C E}$ and $R_{C E}$ were compared with their corresponding modeled $R L T_{T}, D_{C T}$ and $R_{C T}$. The Taguchi method used for DOE has also been used to predict the values of $F_{c}, R_{p}$ and the PFE for the set of parameters selected for the validation. For a combination of process parameters, the predicted values of $F_{c}$ and $R_{p}$ are used to model $R_{M T}$ and $D_{M T}$. Then the predicted value of $P F E$ was used in Eq. (15) to estimate $R_{C T}$ and $D_{C T}$. Then $R L T_{T}$ has been calculated by using Eq. (14). The levels of process parameters selected for validation are the same, but their combinations used were different compared to levels and combinations for parameters selected in DOE. The predicted values of $F_{c}, R_{p}$ and $P F E$ at the process parameters selected for validation are tabulated in 
Table 8 and the theoretical and experimental values of crater radius, crater depth and recast layer thickness are listed in Table 9.

\section{Table 8}

\section{Table 9}

The comparison between the modeled values of crater radius, crater depth and recast layer thickness at the selected process parameters for validation are closer to their corresponding experimental values. The maximum error observed during the prediction of the crater radius, crater depth and recast layer thickness are $10.71 \%, 8.84 \%$ and $12.65 \%$, respectively.

\subsection{Effect of input parameters on modeled crater geometry and recast layer thickness}

For a set of process parameters, the $R_{p}, F_{c}$ and $P F E$ were calculated using Eq. (19), Eq. (20) and Eq. (21), respectively. Then $R_{M T}$ and $D_{M T}$ were obtained from FEM-based numerical simulation using values of $V_{g}, I_{d}, T_{o n} R_{p}$ and $F_{c}$. After that $R_{C T}$ and $D_{C T}$ were obtained using Eq. (11) and $R L T_{T}$ was obtained using Eq. (12). To study the influence of $V_{g}$ on $R_{C T}, D_{C T}$ and $R L T_{T}$, the $I_{d}$ and $T_{o n}$ were kept constant of $16 \mathrm{~A}$ and $100 \mu \mathrm{s}$, respectively. To study the influence of $I_{d}$ on $R_{C T}, D_{C T}$ and $R L T_{T}$, the $V_{g}$ and $T_{o n}$ were kept constant of $40 \mathrm{~V}$ and $100 \mu \mathrm{s}$, respectively. Lastly, to study the influence of $T_{o n}$ on $R_{C T}, D_{C T}$ and $R L T_{T}$, the $V_{g}$ and $I_{d}$ were kept constant of $40 \mathrm{~V}$ and $16 \mathrm{~A}$, respectively. The process parameters, modeled crater geometry and recast layer thickness are listed in Table 10.

\section{Table 10}

\section{Fig.9}

An increase in $V_{g}$ has increases pulse energy, $R_{p}$ and $P F E$ and decreases $F_{c}$. The increase in pulse energy, $R_{p}$ and $P F E$ are responsible for the increase in $R_{C T}$ and the decrease in $F_{c}$ is 
responsible for the decrease in $R_{C T}$. The resultant of these effects result in an increase in $R_{C T}$, as depicted in Fig. 9(a). Similarly, an increase in $I_{d}$ increases pulse energy, $R_{p}$ and $P F E$ and decreases $F_{c}$. The net effect is an increase in $R_{C T}$, as depicted in Fig. 9(b). An increase in $T_{o n}$ increases pulse energy, $R_{p}$ and $F_{c}$ and decreases $P F E$. The increase in pulse energy, $R_{p}$ and $F_{c}$ are responsible for the increase in $R_{C T}$ and the decrease in $P F E$ is responsible for the decrease in $R_{C T}$. The net effect is an increase in $R_{C T}$, as depicted in Fig. 9(c).

\section{Fig.10}

With an increase in $V_{g}$, the increase in pulse energy and $P F E$ are responsible for the increase in $D_{C T}$ and the increase in $R_{p}$ and decrease in $F_{c}$ are responsible for the decrease in $D_{C T}$. The net effect is an increase in $D_{C T}$, as depicted in Fig. 10 (a). With an increase in $\mathrm{I}_{\mathrm{d}}$, the increase in pulse energy and $P F E$ are responsible for the increase in $D_{C T}$ and the increase in $R_{p}$ and decrease in $F_{C}$ are responsible for the decrease in $D_{C T}$. The net effect is an increase in $D_{C T}$, as depicted in Fig. 10(b). In the case of an increase in both $V_{g}$ and $I_{d}, D_{C T}$ increases at a slower rate compared to $R_{C T}$ as the increase in $R_{p}$ is responsible for the increase in $R_{C T}$ and decreases in $D_{C T}$. With an increase in $T_{o n}$, the increase in pulse energy and $F_{C}$ are responsible for the increase in $D_{C T}$ and the increase in $R_{p}$ and the decrease in $P F E$ are responsible for the decrease in $D_{C T}$. The net effect is an increase in $D_{C T}$, as depicted in Fig. 10(c). The combination of the increase in pulse energy and $F_{C}$ together increases $D_{C T}$ at a higher rate with an increase in $T_{o n}$ compared to $V_{g}$ and $I_{d}$.

\section{Fig. 11}

An increase in $V_{g}$ increases the volume of molten material and $P F E$. The increase in the molten material volume is responsible for the increase in $R L T_{T}$ and the increase in $P F E$ is responsible for the decrease in $R L T_{T}$. The increase in $R L T_{T}$ due to the increase in the molten material 
volume is significant and lower $V_{g}$ and the decrease in $R L T_{T}$ due to the increase in $P F E$ is significant at higher $V_{g}$. Fig. 11(a) depicts the net effect of the increase in $V_{g}$ on $R L T_{T}$. The increase in $I_{d}$ also increases the volume of molten material and $P F E$. The decrease in $R L T_{T}$ due to the increase in $P F E$ dominates the increase in $R L T_{T}$ due to the increase in the volume of molten material. Hence, $R L T_{T}$ decreases with the increase in $I_{d}$, as depicted in Fig. 11(b). An increase in $T_{o n}$ increases the molten material volume and decreases PFE. Both the increase in the molten material volume and decrease of $P F E$ are responsible for the increase in $R L T_{T}$. Hence, $R L T_{T}$ increases with an increase in $T_{\text {on }}$, as depicted in Fig. 11(c).

\section{Conclusion}

To model crater morphology for a single discharge in the EDM process, along with the process parameters $V_{g}, I_{d}$ and $T_{o n}$, other important parameters required to predict the crater size are $R_{p}$, $F_{c}$ and $P F E$. In the available previous studies, formulation of $R_{p}, F_{c}$ and PFE in relation to $I_{d}$ and $T_{o n}$ is there. In this work, it has been attempted by inverse finite element method and regression modeling to formulate $R_{p}, F_{c}$ and $P F E$ as a function of $V_{g}$ also along with $I_{d}$ and $T_{o n}$. For the range of different process parameters in which the experiments were conducted, the following conclusions are made:

1. $R_{p}, F_{c}$ and PFE were affected by $V_{g}, I_{d}$ and $T_{o n}$.

2. An increase of all the process parameters resulted in an increase of $R_{p}$. It was ranged from $41.25 \mu \mathrm{m}$ to $141.17 \mu \mathrm{m}$. The contribution made by $T_{o n}$ is highest of $36.33 \%$ followed by $V_{g}$ of $31.92 \%$ and $I_{d}$ of $24.48 \%$ to increase $R_{p}$ obtained from the regression analysis.

3. $\mathrm{F}_{\mathrm{c}}$ was improved by an increase in $T_{o n}$ and deteriorated by an increase in $V_{g}$ and $I_{d}$. It has been ranged from $13.51 \%$ to $29.39 \%$. The contribution made by $T_{o n}$ is highest of $34.65 \%$ followed by $V_{g}$ of $34.12 \%$ and $I_{d}$ of $25.94 \%$ to affect $R_{p}$ obtained from the regression analysis. 
4. PFE had a direct relationship with $V_{g}$ and $I_{d}$ and a converse relationship with $T_{o n}$. It has been ranged from $27.40 \%$ to $55.99 \%$. Contribution to the PFE by $I_{d}$ was highest of $61.97 \%$, followed by $V_{g}$ of $22.40 \%$ and $T_{o n}$ of $11.36 \%$ obtained from the regression analysis.

5. The model developed can predict crater diameter, crater depth and recast layer, which will be helpful to estimate material removal rate and surface roughness.

6. During validation of the model developed, the maximum error found during the prediction of the crater radius, crater depth and recast layer thickness are $10.71 \%, 8.84$ $\%$ and $12.65 \%$, respectively.

\section{Acknowledgment}

Manufacturing Science Lab. (Mechanical Engineering, IIT Kanpur) has provided access to the machine, materials and other resources to conduct this research.

\section{Declarations}

Ethical Approval: There are no studies in this article that include human or animal experiments.

Consent to Participate: All participants in the study provided informed consent.

Consent to Publish: The authors have given consent for this paper to be published.

Authors' Contributions: Bibeka Nanda Padhi has completed the requisite literature review, experiments, simulations, characterization, and analysis to prepare the first draft of the paper. All the authors contributed to the manuscript's conception, critical review and editing.

Funding: Not applicable.

Competing Interests: The authors state that they do not have any conflicts of interest.

Availability of data and materials: Not applicable. 


\section{References}

1. Zhang Z, Zhang Y, Ming W, et al (2021) A review on magnetic field assisted electrical discharge machining. Journal of Manufacturing Processes 64:694-722 . doi: 10.1016/j.jmapro.2021.01.054

2. Shabgard MR, Gholipoor A, Baseri H (2016) A review on recent developments in machining methods based on electrical discharge phenomena. The International Journal of Advanced Manufacturing Technology 2081-2097 . doi: 10.1007/s00170-016-8554-z

3. Das S, Paul S, Doloi B (2020) Feasibility assessment of some alternative dielectric mediums for sustainable electrical discharge machining: a review work. Journal of the Brazilian Society of Mechanical Sciences and Engineering (2020) 42:148 doi: 10.1007/s40430020-2238-1

4. Stief P, Etienne A, Siadat A (2020) Investigation on EDM Plasmas Using Time Spatially-Resolved Optical Emission Spectroscopy. Procedia CIRP 95:183-188 . doi: 10.1016/j.procir.2020.02.303

5. Ahmed A, Fardin A, Tanjilul M (2018) A comparative study on the modelling of EDM and hybrid electrical discharge and arc machining considering latent heat and temperature-dependent properties of Inconel 718. The International Journal of Advanced Manufacturing Technology 94:2729-2737 . doi: 10.1007/s00170-017-11009

6. Uthayakumar M (2021) A review on the performance of the materials by surface modi fi cation through EDM. International Journal of Lightweight Materials and Manufacture 4:127-144 . doi: 10.1016/j.ijlmm.2020.08.002

7. Yue X, Yang Xi (2021) The role of discharge plasma on molten pool dynamics in EDM. 
Journal of Materials Processing and Technology 293:117092 doi: 10.1016/j.jmatprotec.2021.117092

8. Li G, Natsu W, Yu Z (2019) Study on quantitative estimation of bubble behavior in micro hole drilling with EDM. International Journal of Machine Tools and Manufacture 146:103437 . doi: 10.1016/j.ijmachtools.2019.103437

9. Ho KH, Newman ST (2003) State of the art electrical discharge machining (EDM). International Journal of Machine Tools and Manufacture 43:1287-1300 . doi: $10.1016 / \mathrm{S} 0890-6955(03) 00162-7$

10. Shabgard M, Ahmadi R, Seyedzavvar M, et al (2013) Mathematical and numerical modeling of the effect of input-parameters on the flushing efficiency of plasma channel in EDM process. International Journal of Machine Tools and Manufacture 65:79-87 . doi: 10.1016/j.ijmachtools.2012.10.004

11. Snoeys R, Dijck FS van Investigation of EDM Operations by Means of ThermoMathematical Models. CIRP Annals 20:35-36 .

12. Dijck FS van, J. WLD (1974) Heat conduction model for the calculation of the volume of molten metal in electric discharges. Journal of Physics D: Applied Physics 7:899-910 . doi: $10.1088 / 0022-3727 / 7 / 6 / 316$

13. Beck J V (1981) Large time solutions for temperatures in a semi infinite body with a disc heat source. International Journal of Heat and Mass Transfer 24:155-164 . doi: $10.1016 / 0017-9310(81) 90104-6$

14. Jilani ST, Pandey PC (1983) An analysis of surface erosion in electrical discharge machining. Wear 84:275-284 . doi: 10.1016/0043-1648(83)90269-7

15. Dibitonto DD, Eubank PT, Patel MR, Barrufet MA (1989) Theoretical models of the 
electrical discharge machining process . I . A simple cathode erosion model A simple cathode erosion model. Journal of Applied Physics 66:4095-4103 . doi: $10.1063 / 1.343994$

16. Yeo SH, Kurnia W, Tan PC (2007) Critical assessment and numerical comparison of electro-thermal models in EDM. Journal of Material Processing and Technology 3:241251 . doi: 10.1016/j.jmatprotec.2007.10.026

17. Salah N Ben, Ghanem F, Atig K Ben (2006) Numerical study of thermal aspects of electric discharge machining process. International Journal of Machine Tool and Manufacture 46: 908-911

18. Joshi SN, Pande SS (2010) Thermo-physical modeling of die-sinking EDM process. Journal of Manufacturing Processes 12:45-56 . doi: 10.1016/j.jmapro.2010.02.001

19. Singh H (2012) Experimental study of distribution of energy during EDM process for utilization in thermal models. International Journal of Heat and Mass Transfer 55:50535064 . doi: 10.1016/j.ijheatmasstransfer.2012.05.004

20. Ming W, Zhang G, Li H, et al (2014) A hybrid process model for EDM based on finiteelement method and Gaussian process regression. International Journal of Advanced Manufacturing Technology 74:1197-1211 . doi: 10.1007/s00170-014-5989-y

21. Jithin S, Bhandarkar U V, Joshi SS (2017) Analytical Simulation of Random Textures Generated in Electrical Discharge Texturing Jithin. Journal of Manufacturing Science and Emgineering 139:1-14 . doi: 10.1115/1.4037322

22. Patel MR, Barrufet MA, Eubank PT, DiBitonto DD (1989) Theoretical models of the electrical discharge machining process . II . The anode erosion model. Journal of Applied Physics 66:4104-4111 . doi: 10.1063/1.343995 
23. Ikai T, Fujita I, Hashiguchi K (1992) Heat Input Radius for Crater Formation in the Electric Discharge Machining. T IEE Japan 112-D:943-949 . doi: 10.1541/ieejias.112.943

24. Kojima A, Natsu W, Kunieda M (2008) Spectroscopic measurement of arc plasma diameter in EDM. CIRP Annals - Manufacturing Technology 57:203-207 . doi: 10.1016/j.cirp.2008.03.097

25. Kliuev M, Florio K, Akbari M, Wegener K (2019) Influence of energy fraction in EDM drilling of Inconel 718 by statistical analysis and fi nite element crater-modelling. Journal of Manufacturing Processes 40:84-93 . doi: 10.1016/j.jmapro.2019.03.002 


\section{Figures}

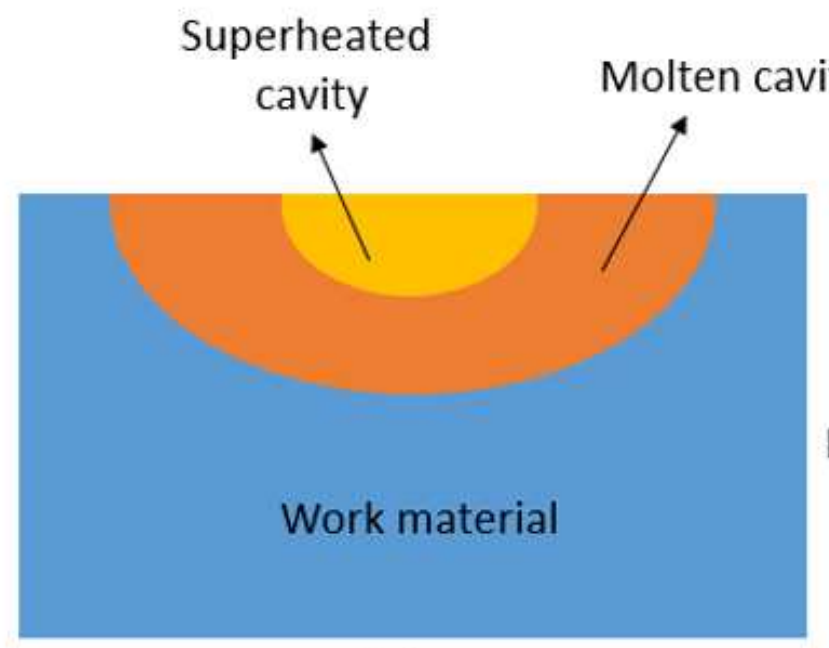

(a)

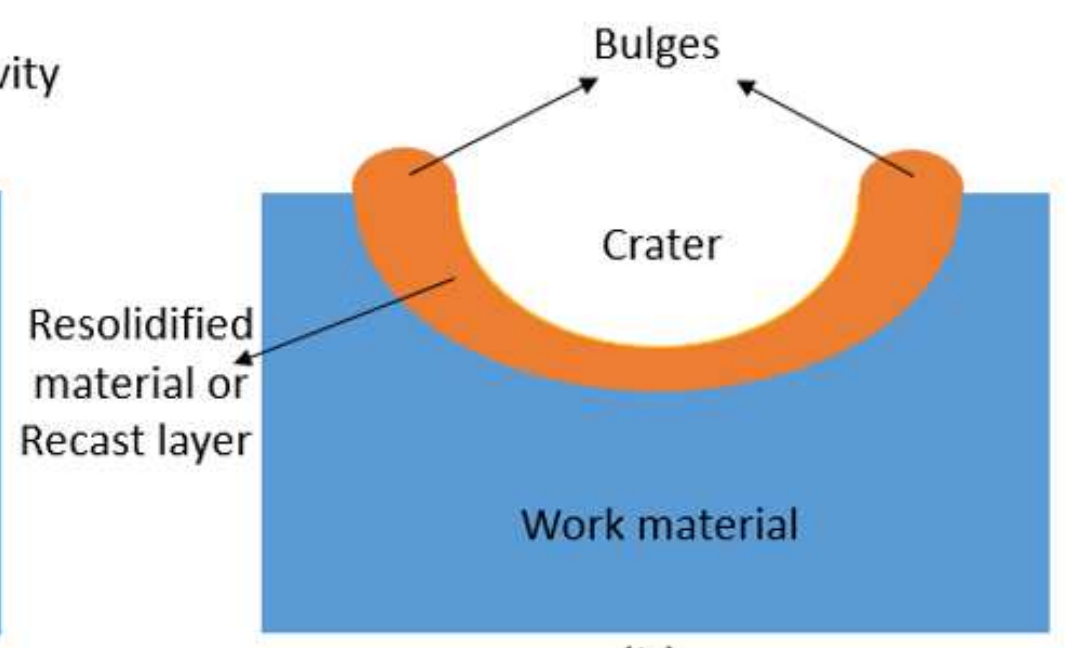

(b)

\section{Figure 1}

Schematic diagram of a molten cavity (a) before and (b) after plasma collapse

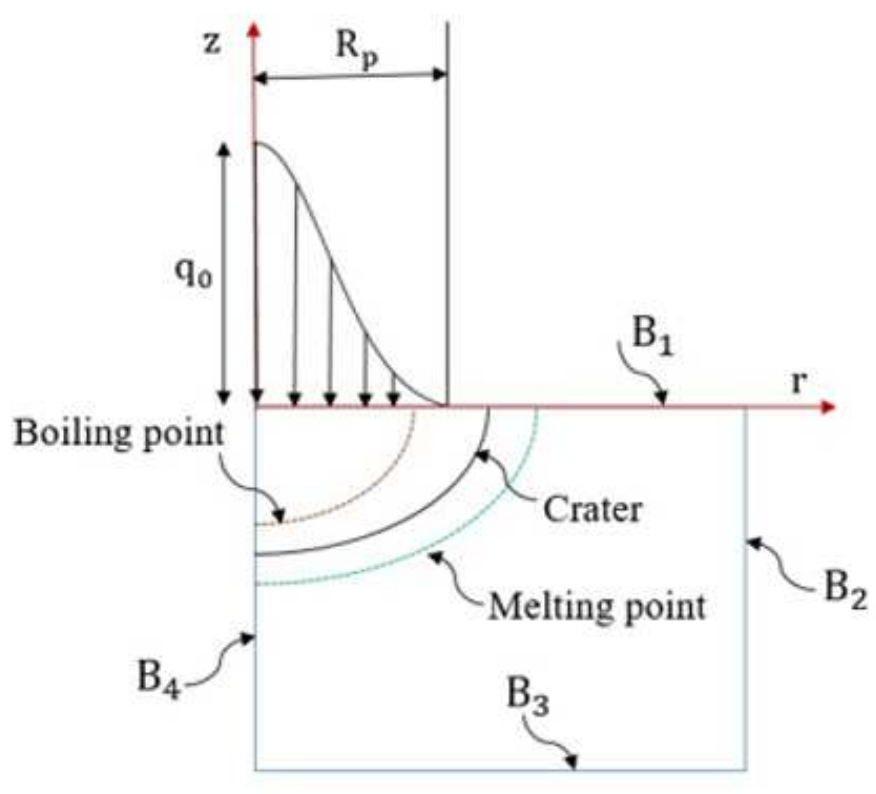

(a)

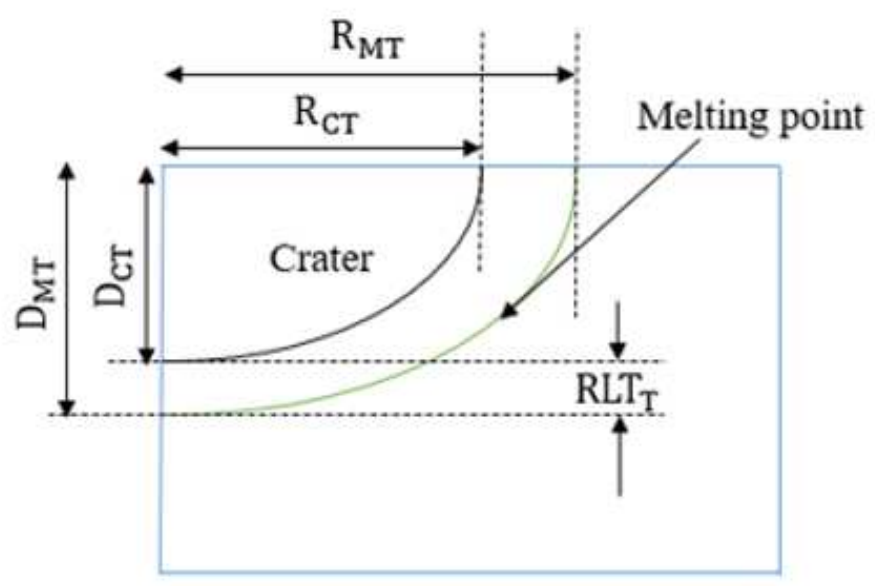

(b)

\section{Figure 2}

(a) Thermal model for a single discharge in EDM process (b) Crater and resolidified melt pool geometry 


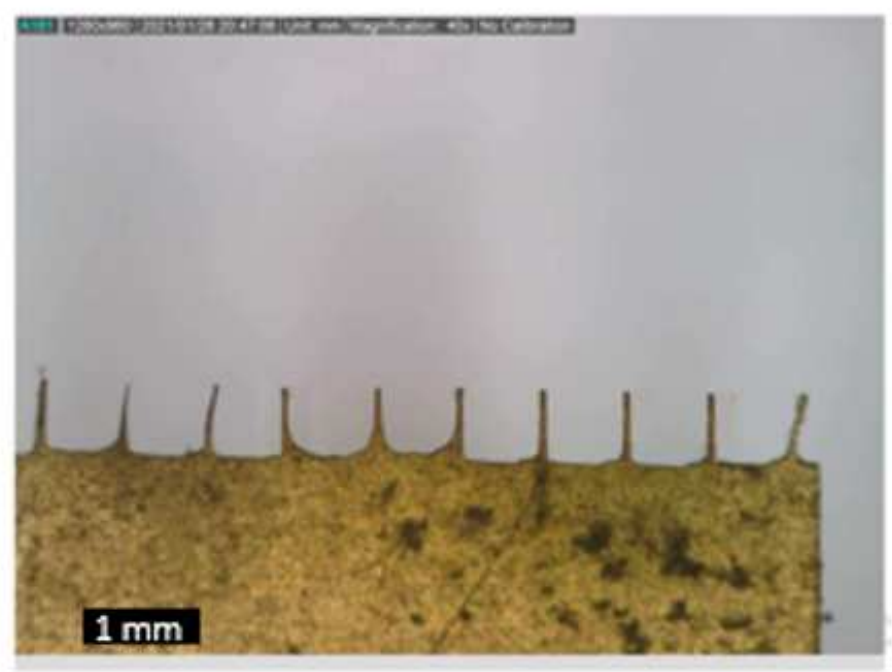

(a)

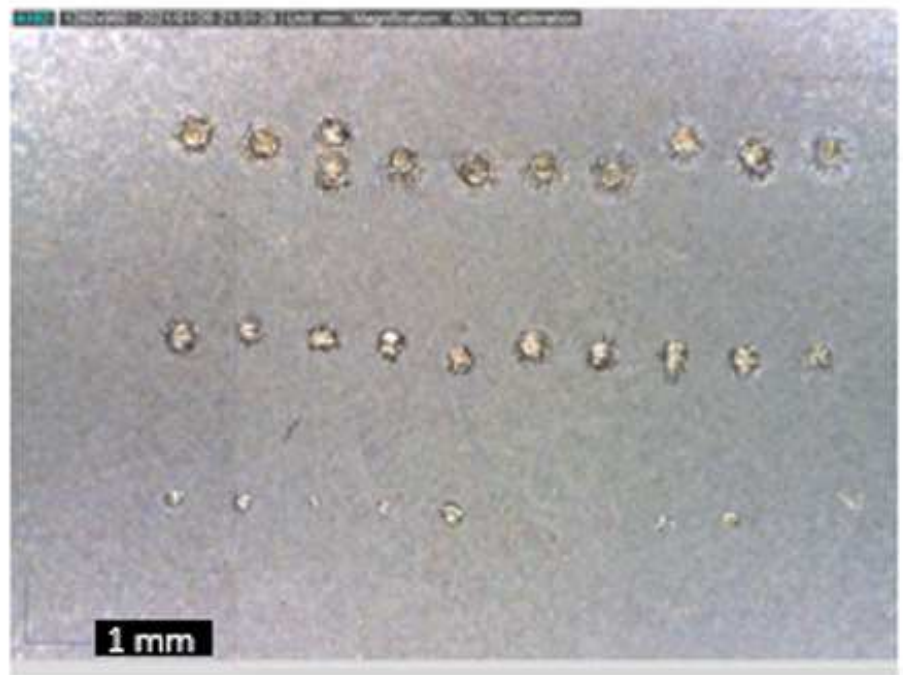

(b)

\section{Figure 3}

(a) Cu tool with micropillars (b) craters formed due to single discharges on D2 steel

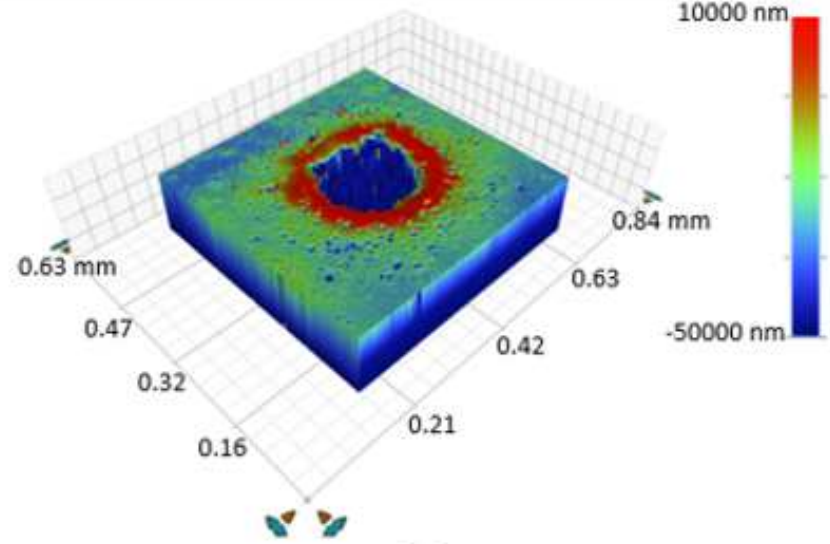

(a)

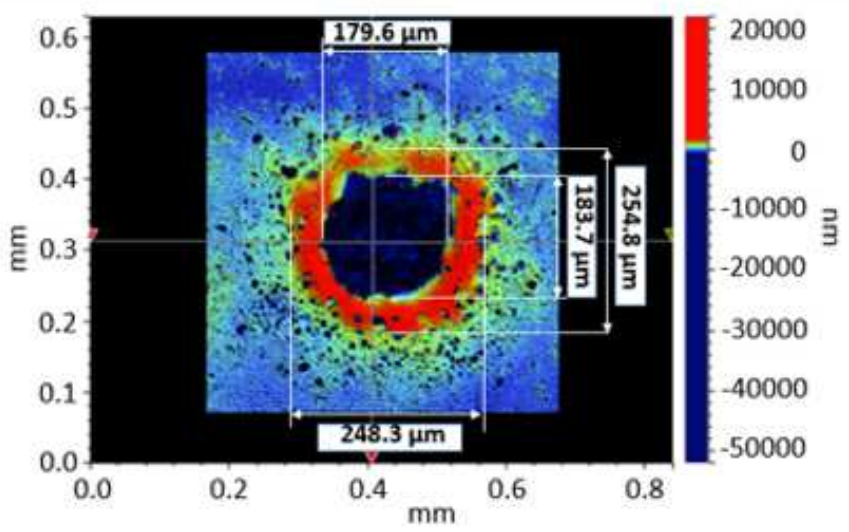

(b)

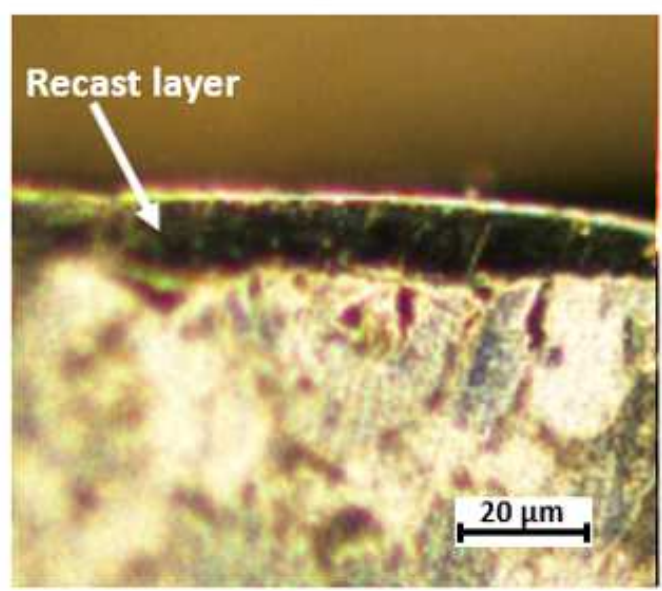

(d)

Figure 4 
(a) 3D profile (b) top view showing the measurement of crater and molten cavity diameters in both $\mathrm{X}$ and $Y$ directions (c) ZX profile showing the depth measurement of the crater and (d) the recast layer thickness of D2 steel at $80 \mathrm{~V}, 16 \mathrm{~A}$ and $150 \mu \mathrm{s}$

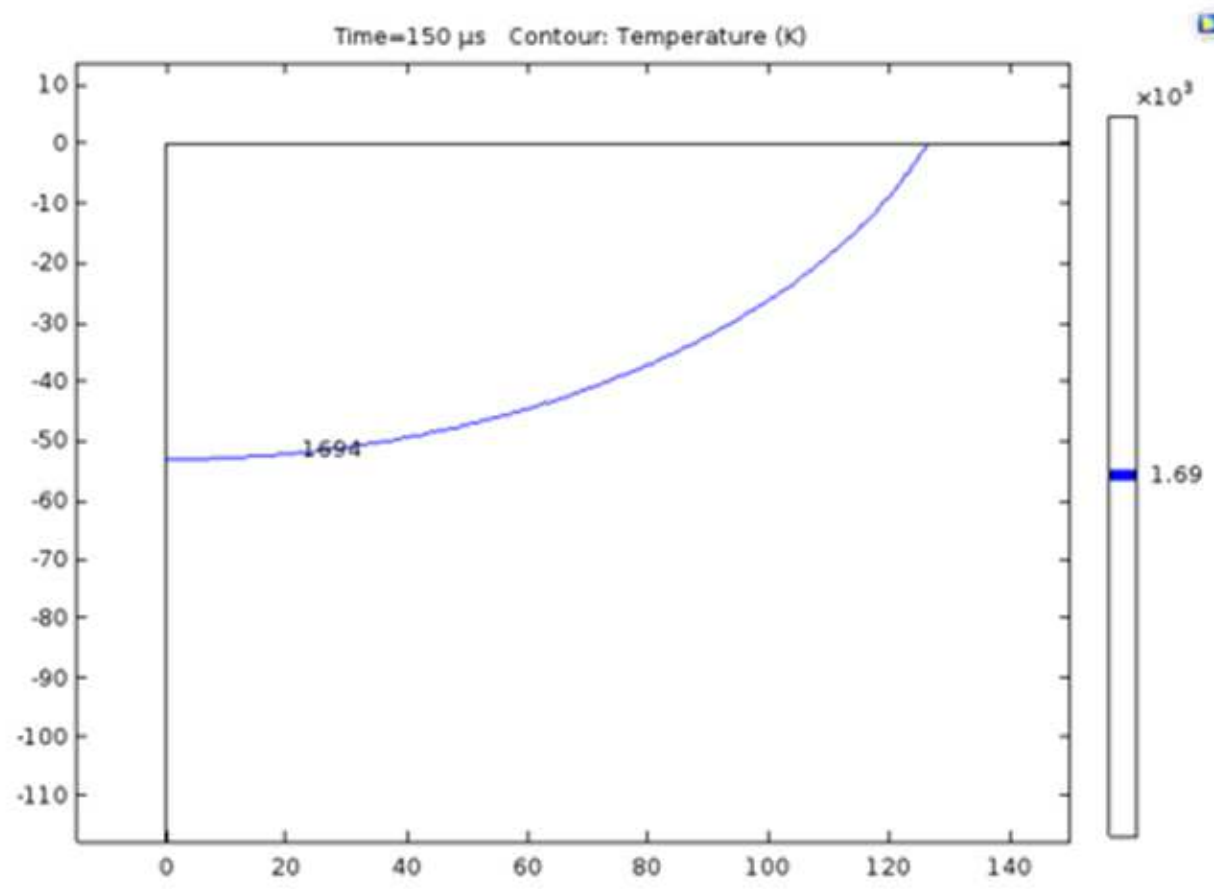

(a)

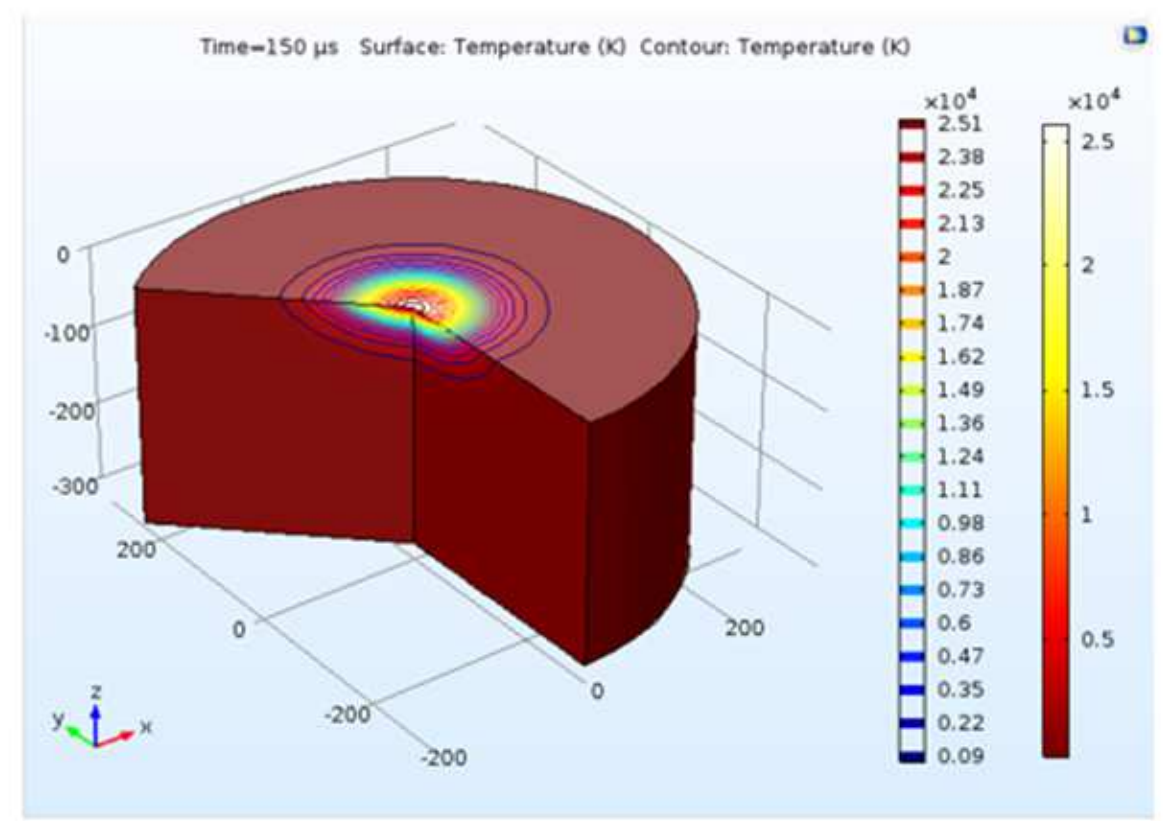

(b)

Figure 5

(a) Simulated isothermal contour at melting point of $1694 \mathrm{~K}$ (b) 3D simulation of temperature distribution for D2 steel at $80 \mathrm{~V}, 16 \mathrm{~A}$ and $150 \mu \mathrm{s}$ 


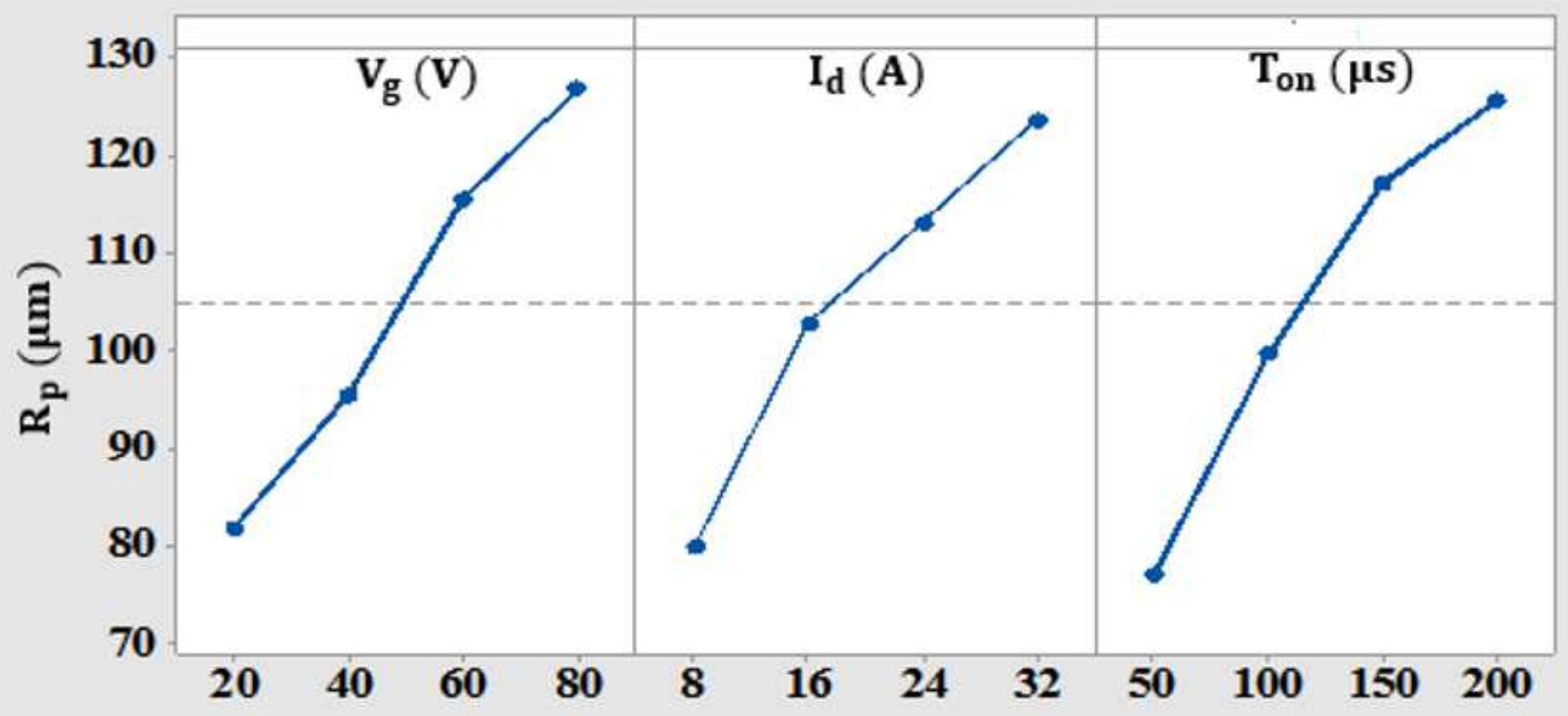

Figure 6

Influence of the process parameters on the plasma radius (Rp)

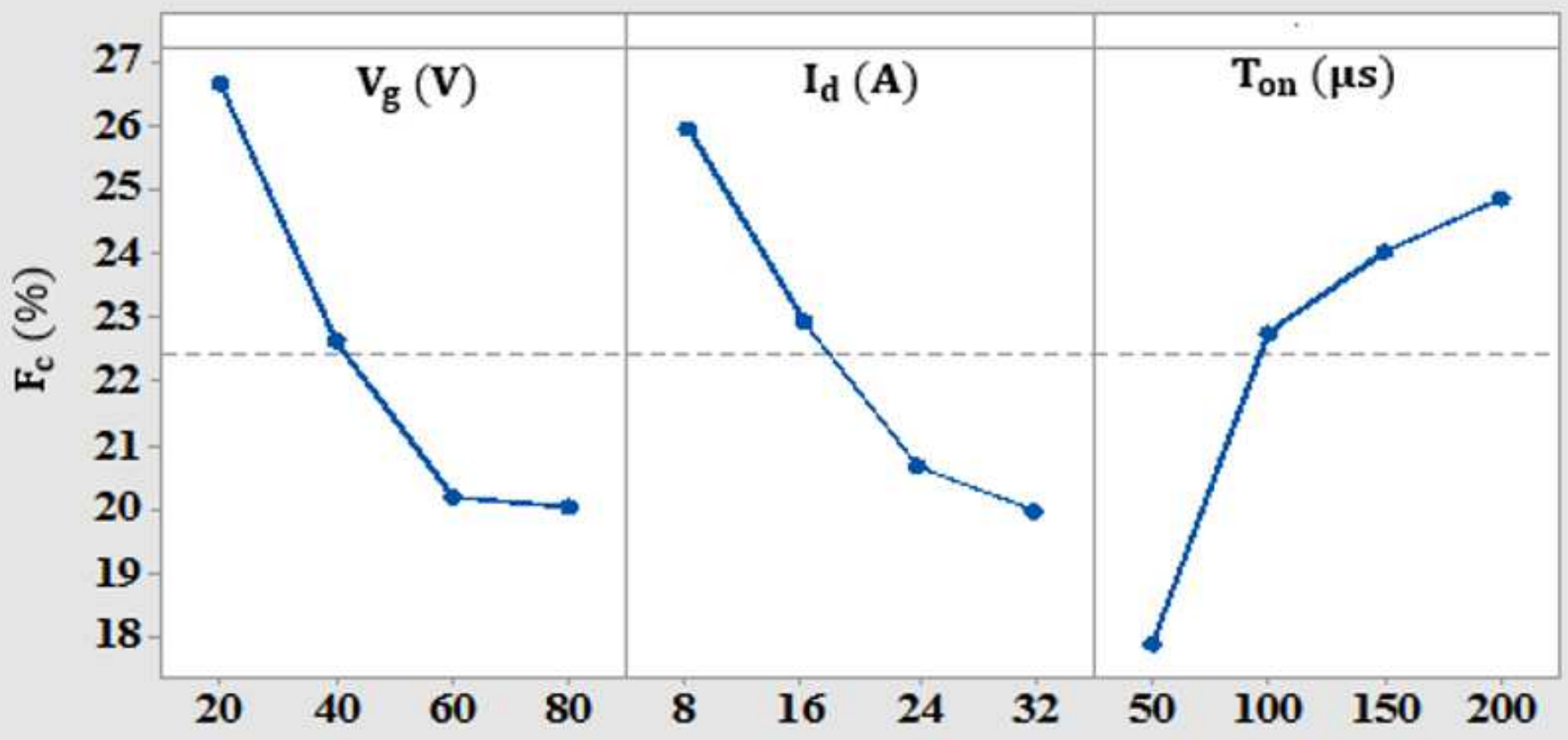

Figure 7

Influence of process parameters on the fraction of energy input to the workpiece (Fc) 


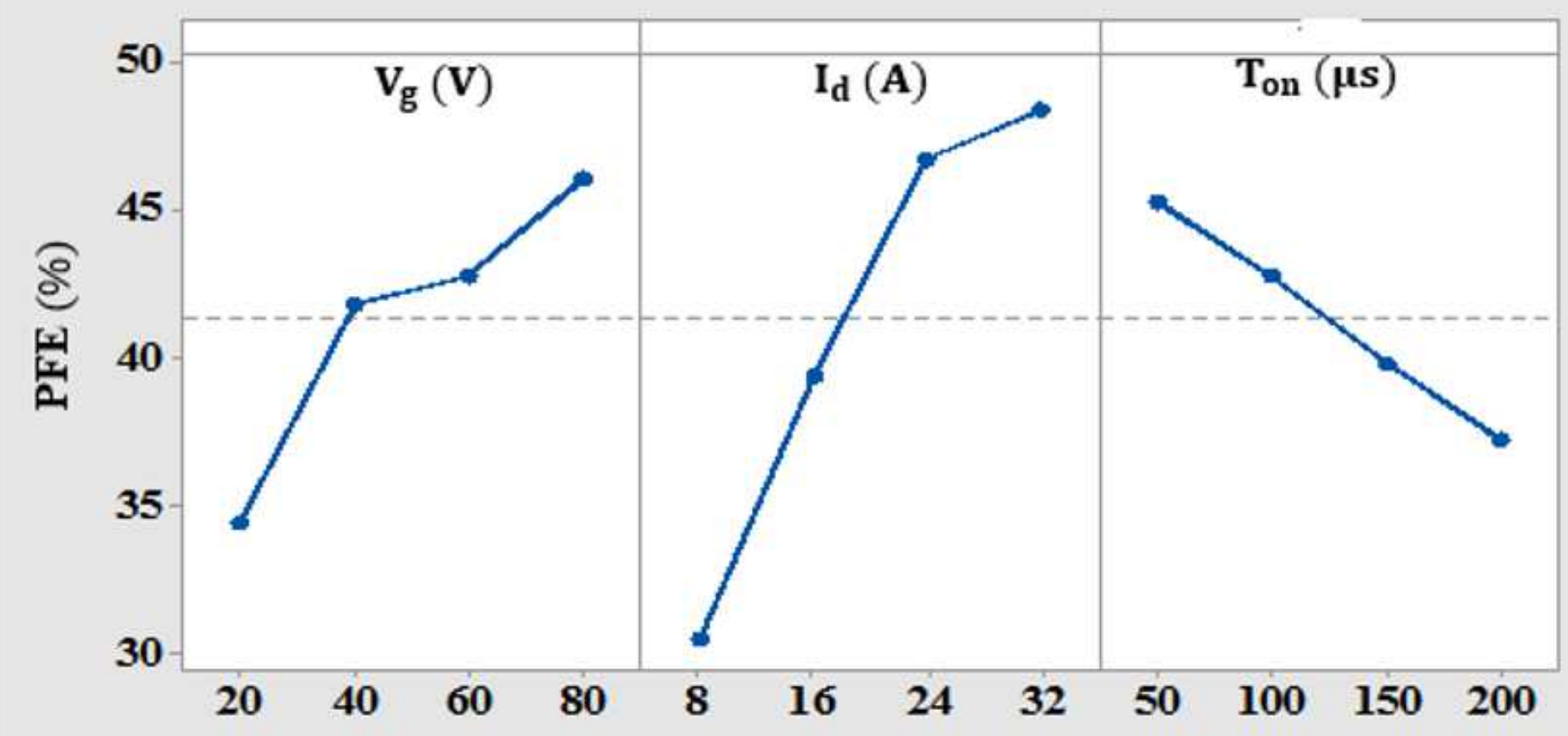

Figure 8

Influence of the process parameters on the plasma flushing efficiency (PFE)

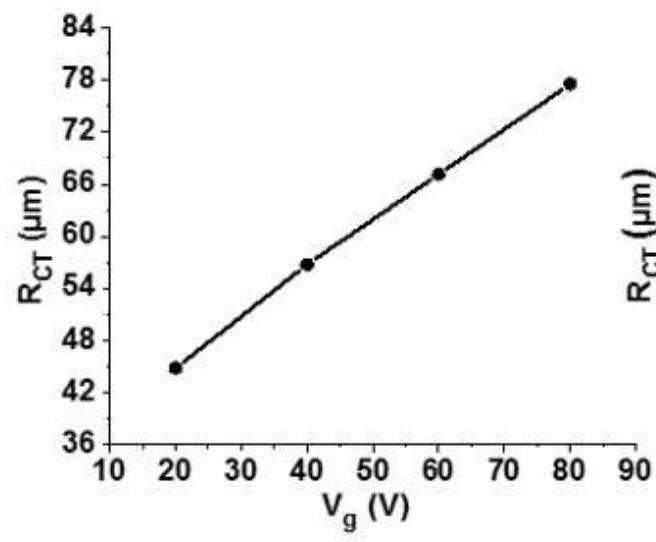

(a)

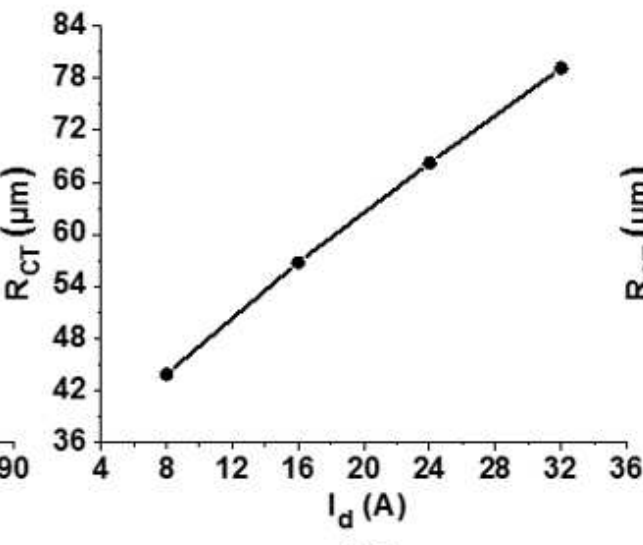

(b)

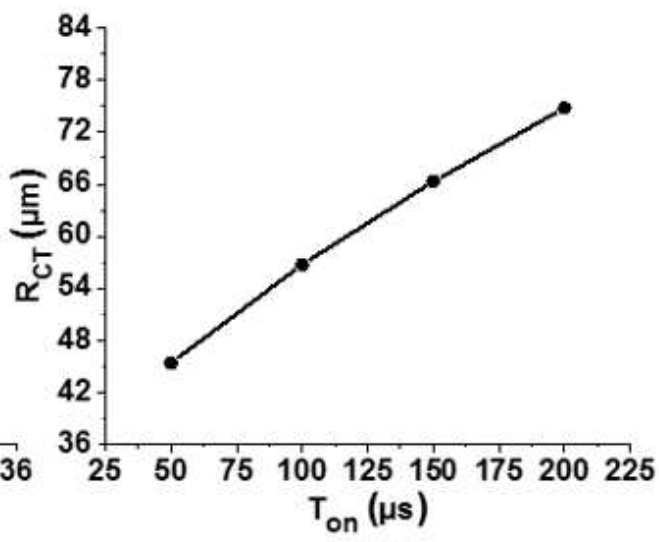

(c)

\section{Figure 9}

The influence of (a) gap voltage ( $\mathrm{Vg})(\mathrm{b})$ discharge current (Id) and (c) pulse on time (Ton) on crater radius $(\mathrm{RCT})$. 


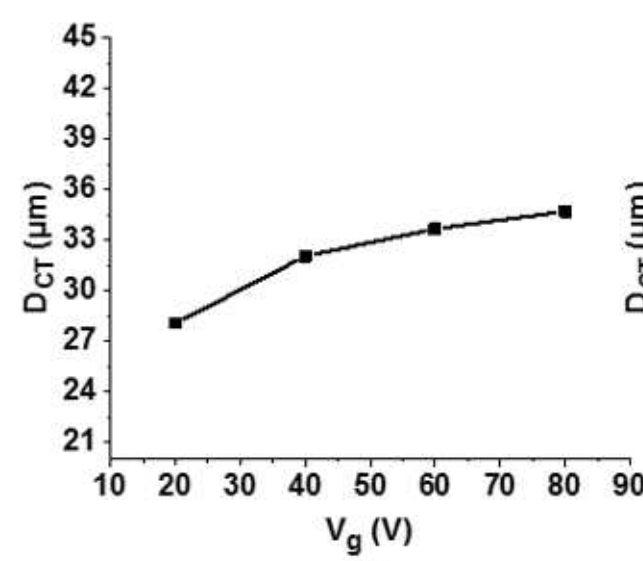

(a)

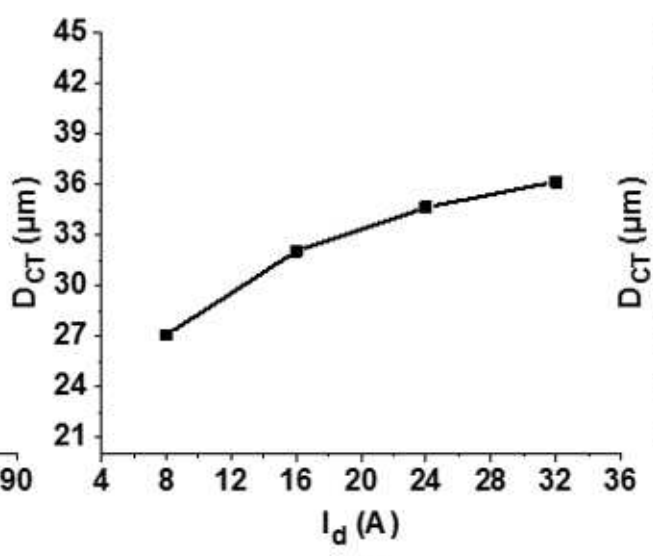

(b)

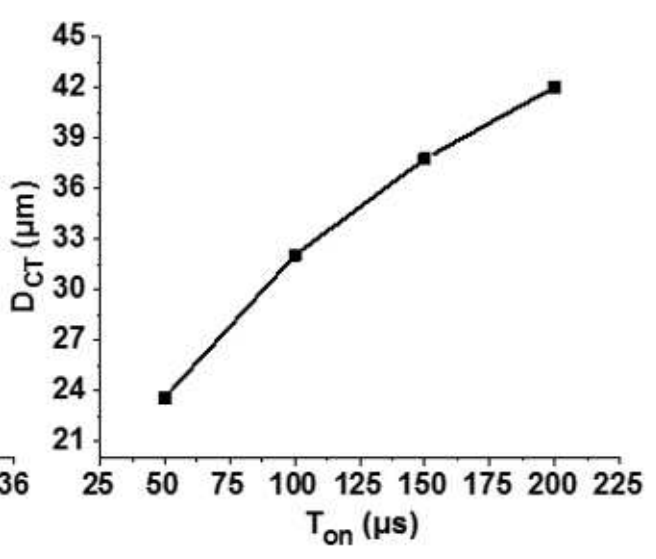

(c)

\section{Figure 10}

The influence of (a) gap voltage $(\mathrm{Vg})$ (b) discharge current (Id) and (c) pulse on time (Ton) on crater depth (DCT).

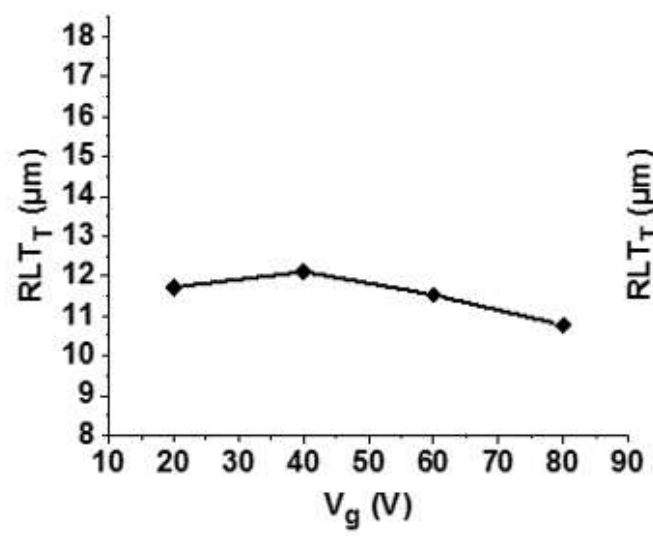

(a)

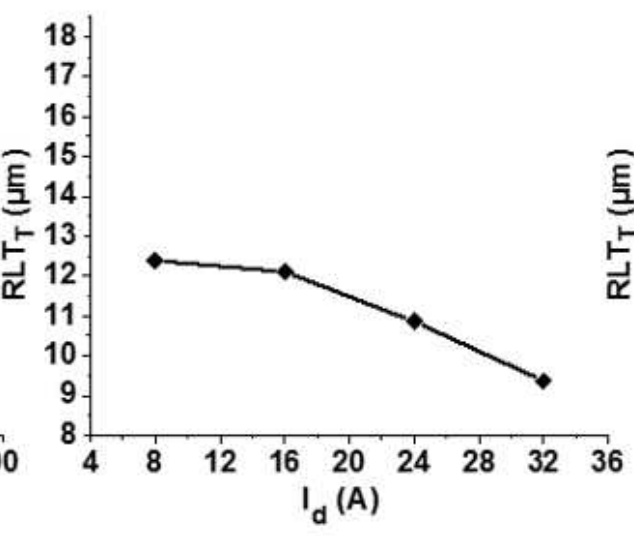

(b)

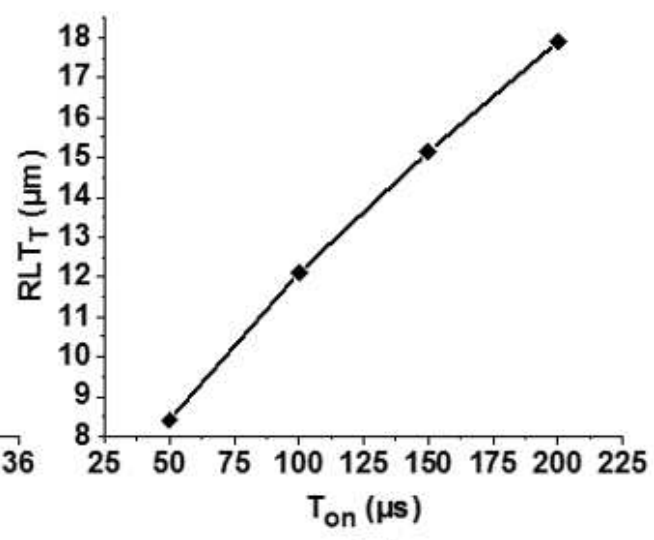

(c)

\section{Figure 11}

The influence of (a) gap voltage ( $\mathrm{Vg})$ (b) discharge current (Id) and (c) pulse on time (Ton) on recast layer thickness (RLTT)

\section{Supplementary Files}

This is a list of supplementary files associated with this preprint. Click to download.

- Tables.docx 